Please do not remove this page

RMIT

UNIVERSITY

\title{
Utilization of agricultural by-products as fillers and reinforcements in ABS
}

Chevali, Venkata; Fuqua, Michael; Huo, Shanshan; Ulven, Chad

https://researchrepository.rmit.edu.au/esploro/outputs/9921861836401341/filesAndLinks?institution=61RMIT_INST\&index=null

Chevali, V., Fuqua, M., Huo, S., \& Ulven, C. (2010). Utilization of agricultural by-products as fillers and reinforcements in ABS. SAE International Journal of Materials and Manufacturing, 3(1), 221-229.

https://doi.org/10.4271/2010-01-0424

Document Version: Published Version

Published Version: https://doi.org/10.4271/2010-01-0424

Repository homepage: https://researchrepository.rmit.edu.au

(C) 2010 SAE International

Downloaded On 2023/04/26 19:21:59 +1000

Please do not remove this page 
Thank you for downloading this document from the RMIT Research Repository.

The RMIT Research Repository is an open access database showcasing the research outputs of RMIT University researchers.

RMIT Research Repository:http://researchbank.rmit.edu.au/

\section{Citation:}

Chevali, V, Fuqua, M, Huo, S and Ulven, C 2010, 'Utilization of agricultural by-products as fillers and reinforcements in ABS', SAE International Journal of Materials and Manufacturing, vol. 3, no. 1, pp. 221-229.

See this record in the RMIT Research Repository at:

https://researchbank.rmit.edu.au/view/rmit:19321

Version: Published Version

Copyright Statement: (c) 2010 SAE International

Link to Published Version:

http://dx.doi.org/10.4271/2010-01-0424 


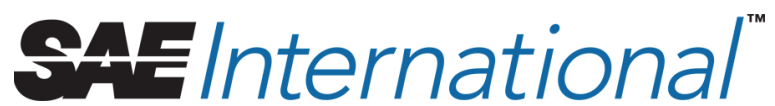

\section{Utilization of Agricultural By-products as Fillers and Reinforcements in ABS}

\author{
Venkata S. Chevali, Michael A. Fuqua, Shanshan Huo and Chad A. Ulven \\ Department of Mechanical Engineering, North Dakota State University
}

Copyright (C) 2010 SAE International

\begin{abstract}
Lignocellulosic agricultural by-products can be utilized for an array of biocomposite material applications. Biocomposite properties can approach those of synthetic conventional composites. They are highly suitable for automotive applications, where the thrust is toward fuel economy, weight-reduction, and higher renewability. A common automotive polymer for biocomposite application is alloyed acrylonitrile butadiene styrene (ABS), whose extensive usage can be attributed to its exceptional balance of properties. However, the low sustainability of ABS in environmental degradation entails the addition of fillers. In this study, the UV blocking properties of lignin component of natural fibers will be analyzed for their use as additives in a natural ABS grade and will be compared to an ABS grade compounded with a traditional UV inhibitor.
\end{abstract}

\section{INTRODUCTION}

Biocomposite materials combine the advantage of reducing the usage of synthetic petroleum products by using a renewable natural resource and offering structural performance similar to those of synthetic composites $[\underline{1}, \underline{2}]$. Biocomposite materials also feature competitive pricing because of their economical natural component, in addition to adding value to commodity polymers, such as polypropylene and polyethylene $[\underline{3}, \underline{4}, \underline{5}]$. These polymers allow easy incorporation of the natural lignocellulosic fiber and allow an additional fiber chemical treatment [4] due to their low initial cost, which explains their widespread usage. Research endeavors have also extended to various other thermoplastic matrices, however with mixed results.

Apart from polyolefins, acrylonitrile butadiene styrene (ABS) in its standard and alloyed grade finds many applications in the automotive plastic components [] $]$. ABS is a styrenic polymer that is a combination of rubbery toughener (polybutadiene) particles dispersed in a styrene-acrylonitrile (SAN) phase [7]. ABS possesses the highest impact resistance within engineering polymers, with high toughness and the flexibility of processing that includes injection and compression molding, rotomolding, blow molding, etc [6]. The common applications for ABS are enclosures for electronic equipments, and automotive parts. They are considered to be alternatives for HDPE, PP and nylon. Table 1 lists the properties of unreinforced ABS. In spite of possessing superior properties and easy moldability that strengthen its position as an engineering polymer, the cost $/ \mathrm{kg}$ of the material partly prohibits its usage in commodity applications.

ABS on environmental weathering shows brittleness and yellowing [8]. The unsaturated bond in acrylonitrile side group favors thermo-oxidative degradation by the formation of imide chromophores, which causes yellowing over time under conditions of outdoor exposure. Moreover, the unsaturated bond in butadiene backbone contributes to thermal, thermo-oxidative, or photo-oxidative degradation, and readily shows chain scission and crosslinking leading to embrittlement.

Specifically, the discoloration and instability of ABS to outdoor weathering is primarily are attributed to the unsaturated carbonyl and double bonds in the butadiene phase and in the styrene acrylonitrile dispersion [9]. Tiganis et al. [10] investigated the thermo-oxidative degradation of ABS blends, and reported the degradation to be concentrated at the surface that showed microcracks initiating from existing flaws in the degraded polymer surface layer and causing fracture in mechanical testing. They also reported the thermal degradation of the SAN phase being dictated by physical aging and thermo-oxidative degradation, but mechanical properties in the degraded material being a function of the 
polybutadiene phase, which entails the addition of stabilizers to optimize performance. Davis et al. [11] conducted thermal degradation studies in ABS resins and found the degradation of the polybutadiene phase to undergo photolysis of the methylene bond in the trans-1,4-polybutadiene, which creates radicals that oxidize to produce carbonyl and hydroxyl byproducts. Pickett et al. [12] performed accelerated weathering on several engineering thermoplastics, including $\mathrm{ABS}$, and found it to possess a high non-linearity in degradation with increase irradiance intensities. They also argued that shorter wavelengths would cause higher degradation in the polymer, with aromatic polymers; such as ABS is expected to have absorption maxima at wavelength lower than $300 \mathrm{~nm}$.

Table 1. A List of ABS properties [6].

\begin{tabular}{ll}
\hline Property & Value \\
\hline Price $(\mathrm{US} \$ / \mathrm{kg})$ & $5.00-5.10$ \\
Density $\left(\mathrm{g} / \mathrm{cm}^{3}\right)$ & $1.01-1.21$ \\
Fracture Toughness $\left(\mathrm{MPa} . \mathrm{m}^{1 / 2}\right)$ & $1.20-4.20$ \\
Service Temperature $\left({ }^{\circ} \mathrm{C}\right)$ & $-18-90$ \\
Glass Transition Temperature $\left({ }^{\circ} \mathrm{C}\right)$ & 110 \\
Moisture Absorption $(\%$ dry mass) & $0.1 \%-0.5 \%$ \\
\hline
\end{tabular}

The addition of inexpensive natural filler to ABS is thus an opportunity to utilize the cellulosic part of the fiber for strength, and the lignin component for retardation of thermal and ultraviolet degradation. Moreover, this study shows an increased weathering performance without sacrificing mechanical strength. Specifically, this investigation focuses on analyzing the performance of a natural fiber-reinforced $\mathrm{ABS}$ vis-à-vis a carbon black-filled, heat-stabilized ABS grade. The unreinforced ABS grade is treated as a baseline for properties.

\section{MATERIALS AND EXPERIMENTAL PROCEDURE}

\section{MATERIALS}

ABS was obtained from Thai ABS plastics in natural (Porene AP102, Thai Petrochemical Company) and black grade (Porene AP102W, Thai Petrochemical Company), with a UV stabilizer (carbon black) [13]. The melt flow index for these polymers was about $20.0 \mathrm{~g} / 10 \mathrm{~min}$. The nomenclature used in this paper is ABS-N for natural colored ABS, ABS-B denotes carbon black filled ABS, and ABS-S stands for ABS compounded with bio-based filler. A bio-based natural fiber derived from a hull-type structure was used in this study, with an average of about 45 wt. $\%$ cellulose and 22 wt. \% lignin.

\section{PROCESSING}

The as-received ABS was compounded with 20 wt. \% of lignocellulosic fiber, which was selected based on previous studies. The fiber was subjected to size-reduction in a centrifugal mill to approximately $0.25 \mathrm{~mm}$. The polymer and the fiber were compounded in a co-rotating twin-screw extruder (Leistritz Micro 18 GL-40 D), and pelletized after being water-cooled and blow-dried using compressed air. The compounded pellets were injection molded (Technoplas SIM 5080) using vendor-recommended temperature profiles, as ASTM D-638 type specimens. In all cases, ABS-N, molded with similar processing parameters was used as a control for properties.

\section{ULTRAVIOLET AND HUMIDITY CONDITIONING}

ABS-N, ABS-B, and ABS-S specimens were conditioned according to ASTM G 154-06 in an accelerated weathering tester (Q-UV, Q-Lab Inc.) [14] with UVA-340 lamps with an approximate irradiance of $1.55 \mathrm{~W} / \mathrm{m}^{2} / \mathrm{nm}$, at a wavelength of $340 \mathrm{~nm}$. A common cycle suggested in the ASTM Standard was used, which was $8 \mathrm{~h}$ of UV exposure at $70 \pm 3{ }^{\circ} \mathrm{C}$ black panel temperature followed by a $4 \mathrm{~h}$ condensation at $50 \pm 3$ ${ }^{\circ} \mathrm{C}$ black panel temperature. The Q-UV weathering tester simulates the harshest environmental conditions of ultraviolet radiation portion of sunlight, hot condensation, and high temperature, which cause the maximum degradation in plastics that are used for outdoor applications. These specimens were exposed to 1) $168 \mathrm{~h}$ (14 cycles) and 2) $84 \mathrm{~h}$ (7 cycles).

\section{MECHANICAL TESTING}

\section{Tensile Testing}

Type-I dogbone specimens were tested according to ASTM D 638 [15] at room temperature with a minimum of four specimens for each material. The ultimate tensile strength (UTS, $\left.\sigma_{\mathrm{T}}\right)$, Young's modulus $\left(E_{\mathrm{T}}\right)$, percentage extension to failure for ABS-S, and strain at maximum stress are reported.

\section{Dynamic mechanical analysis}

Coefficient of linear thermal expansion (CLTE) was measured using a dynamic mechanical analyzer (DMA Q800, TA Instruments Inc.) [16] in the controlled force module that utilized a tensile film clamp. The specimen was held in the clamp using a minimal preload force, and was subjected to a temperature ramp of about $5{ }^{\circ} \mathrm{C} / \mathrm{min}$ from room temperature to $150{ }^{\circ} \mathrm{C}$. Displacement was plotted as function of temperature, and the slope was determined in a relatively 
linear region. The slope was then translated to a CLTE value using $\alpha=\left(1 / l_{0}\right)(\Delta l / \Delta T)$, where $\alpha$ is the CLTE, $\Delta l$ and $l_{0}$ are the change in length and initial lengths, and $\Delta T$ is the temperature difference.

\section{CHARACTERIZATION}

\section{Fourier-transform Infrared Spectroscopy}

FTIR was used to observe the compositional changes in the specimen caused by the environmental conditioning. An FTIR (Nicolet 6700, Thermo-electron Corporation) [17] was used in the attenuated total reflectance (ATR) mode on a ZnSe crystal, with a resolution of $4.0 / \mathrm{cm}$ and 32 scans per specimen. All spectra were post-processed with an ATR correction in the vendor software.

\section{Colorimetry}

A bench-top colorimeter (Macbeth ColorEye Model \# 7000) [18] was used to monitor the color change $(\Delta X, \Delta Y, \Delta Z)$ or increasing yellowness over the unexposed specimens. Yellowness is an optical property of a polymer that is a measure of the chromatic deviation from whiteness in wavelengths ranging from $570 \mathrm{~nm}-580 \mathrm{~nm}$ [19]. A CIE $\mathrm{L} * \mathrm{a} * \mathrm{~b} *$ scale was used to measure the specimen color, which was converted to $X Y Z$ scale for calculating yellowness index, according to ASTM E 313-05 [20] using the following equation

$$
\text { Yellowness Index }=100(1.28 \Delta X-1.06 \Delta Z) / \Delta Y
$$

\section{RESULTS AND DISCUSSION}

\section{CHARACTERIZATION}

The observed mass loss after a UV/condensation treatment was approximately $0.260 \pm 0.008 \%, 0.360 \pm 0.021 \%$, and $0.390 \pm 0.013 \%$ in ABS-N, ABS-B, and ABS-S specimens. Following retrieval of the specimens from the weathering test chamber, the specimen were weighed, and conditioned in a desiccator till they regained equilibrium mass. All analytical measurements were performed after this conditioning.

\section{Fourier-transform Infrared Spectroscopy}

FTIR spectra of the unexposed and Q-UV conditioned specimens were acquired in the ATR mode. Fig. 1.(a) shows the $900-1000 \mathrm{~cm}^{-1}$ region of the spectra, which represents the rocking modes of $\mathrm{CH}_{2}$ that constitutes trans- 1,4 butadiene $\left(\sim 960 \mathrm{~cm}^{-1}\right)$ and 1,2 butadiene $\left(\sim 910 \mathrm{~cm}^{-1}\right)$ []. The $960 \mathrm{~cm}^{-1}$ peak undergoes severe degradation in intensity, whereas $910 \mathrm{~cm}^{-1}$ peak is comparatively less sensitive to degradation. As shown in the unexposed condition, the $910 \mathrm{~cm}^{-1}$ and $962 \mathrm{~cm}^{-1}$ peaks are distinct, which can be treated as a baseline. However, with a $168 \mathrm{~h}$ Q-
UV treatment in ABS-N, the intensity of 910 peak decreases, as expected, but the 960 peak completely disappears (Fig. 1(b)). This observation can be explained by considering the similar roles of carbon black in ABS-B and the extremely photo-stable lignin component of the natural fiber in ABS-S. These components actively shield the exposure, and thus preclude immediate initiation of oxidation. The absence of either anti-oxidant in ABS-N causes the observed effect (note that the ABS-N after exposure required a secondary y-axis for absorbance in order to overlap the results for discussion purposes).

On the other hand, the intensities of both peaks in ABS-B and ABS-S decrease, but recognizable peaks exist and show minimal peak-shift. This observation leads to the argument of a lower chain scission and other degradation mechanisms over ABS-N's basic molecular structure with the addition of filler. Nevertheless, ABS-S in the exposed condition shows lower absorbance of the $\mathrm{CH}_{2}$ when compared to the unexposed material (Fig. 1.(c)).

Fig. 2 shows the FTIR spectra of the unexposed and $168 \mathrm{~h}$ exposed materials, and focuses on the $2850 \mathrm{~cm}^{-1}\left(\mathrm{CH}_{2}\right)$ and $2233 \mathrm{~cm}^{-1}(\mathrm{C} \equiv \mathrm{N})$ bands, which are the representative of the molecular structure of ABS. The intensities of the $0 \mathrm{~h}$ exposed materials (Fig. 2(a) and 2(b)) was higher than those of168 h-exposed samples. This decrease is consistent with the degree of degradation in the material. Lower peak intensities and convoluted peaks in ABS-S and ABS-B materials at 168 h-exposed case suggest higher degree of chain scission and onset of degradation especially in the $\mathrm{CH}_{2}$ groups. Moreover, the relative band intensities for the $2233 \mathrm{~cm}^{-1}$ peak for the ABS-S and ABS-B in both exposure cases remains nearly constant, while a decrease in nitrile $(\mathrm{C} \equiv \mathrm{N})$ absorbance and peak shift is observed in the neat material. This change in peak characteristics also indicates that ABS-N is more susceptible to damage, over the ABS-S composite. 


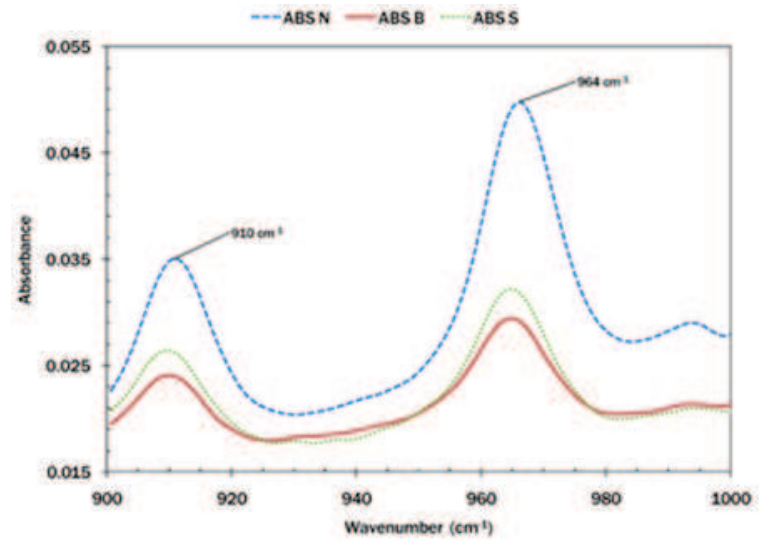

(a)

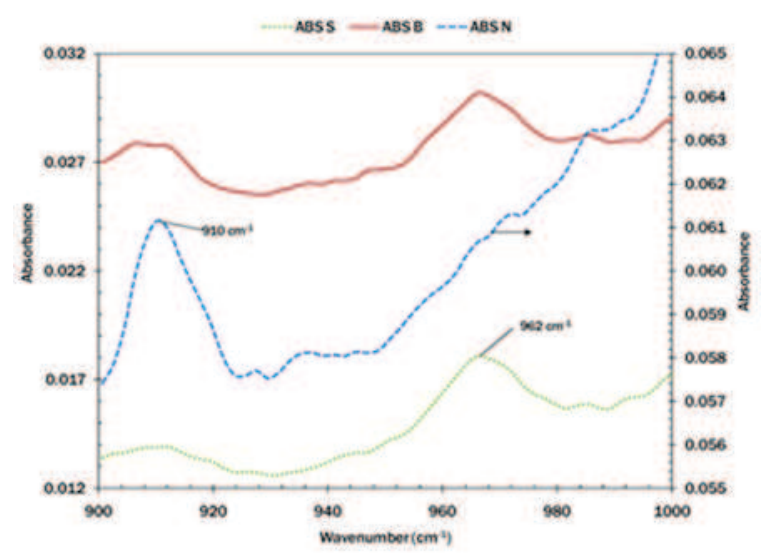

(b)

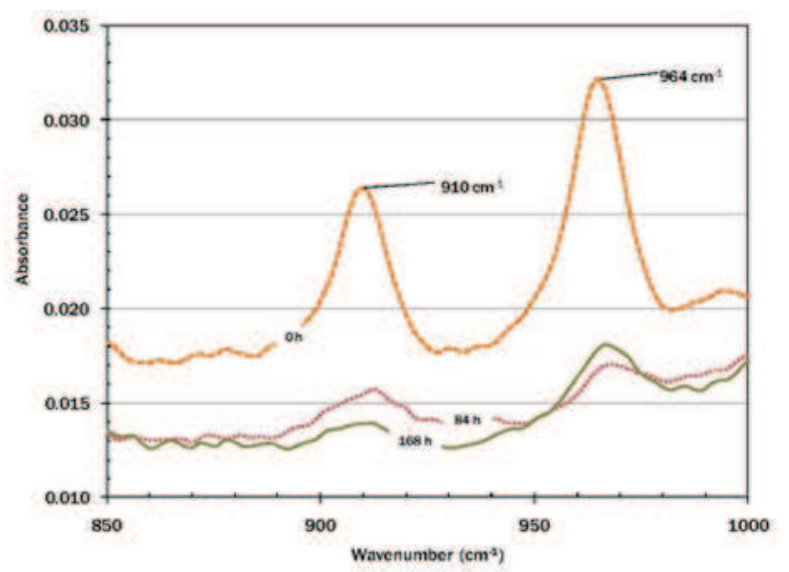

(c)

Fig. 1. (a) FTIR spectra of 0 h exposed materials in 900 $1000 \mathrm{~cm}^{-1}$ (butadiene) region (b) FTIR spectra of $168 \mathrm{~h}$ QUV exposed materials in butadiene region, highlighting the $910 \mathrm{~cm}^{-1}$ and $962 \mathrm{~cm}^{-1}(C=C)$ peaks, and (c) the absorbance variation in the ABS-S over three exposure cases.

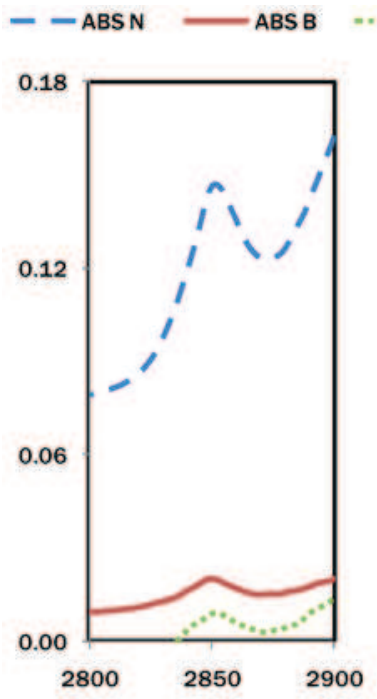

(a)

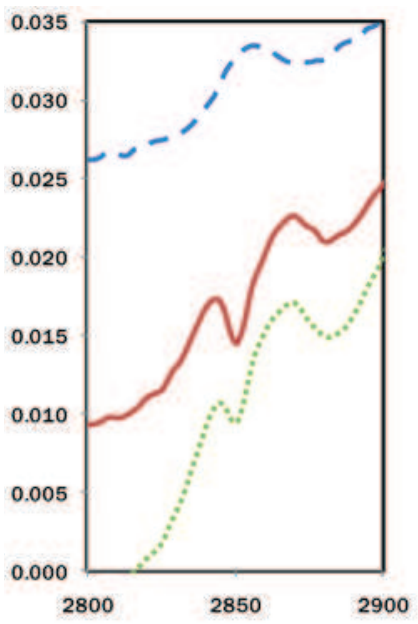

(c)

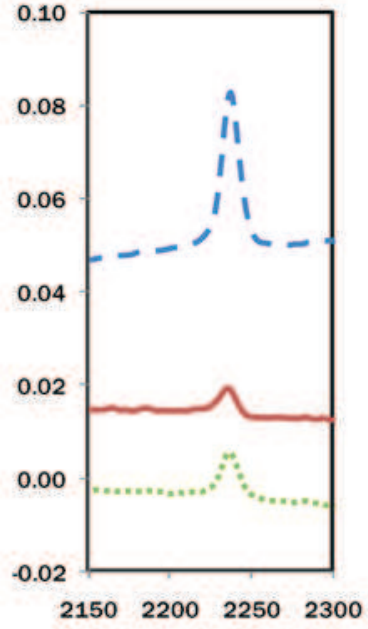

(b)

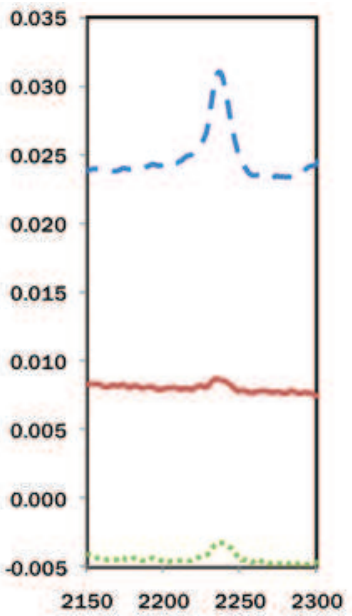

(d)

Fig. 2. FTIR spectra of three materials in 0 h exposure (a) $2850 \mathrm{~cm}^{-1}$ band, (b) $2233 \mathrm{~cm}^{-1}$ band, and in the 168 h exposure condition (c) $2850 \mathrm{~cm}^{-1}$ band, and (d) 2233 $\mathrm{cm}^{-1}$ band.

\section{ABS-S DEGRADATION}

The two chief indicators of hydrolytic and oxidative degradation are the hydroxyl $(\mathrm{O}-\mathrm{H})$ band around $3300 \mathrm{~cm}^{-1}$ and the carbonyl $(\mathrm{C}=\mathrm{O})$ around the $1700-1750 \mathrm{~cm}^{-1}$ region. An increase in the hydroxyl band corresponds to hydrolysis or plasticization of the matrix material when exposed to humidity or moisture. Similarly, an increase in the carbonyl band absorbance indicates formation of oxidation products by Norrish type reactions. 
Fig. 3(a) illustrates the absorbance of ABS-S at $0 \mathrm{~h}, 84 \mathrm{~h}$, and $168 \mathrm{~h}$ levels of Q-UV conditioning. An increase in the absorbance of $\mathrm{O}-\mathrm{H}$ is caused due to formation of byproducts during the photo-oxidation. In addition, a wide band of the hydroxyl $\left(\sim 3150-3600 \mathrm{~cm}^{-1}\right)$ is in part contributed by the cellulosic part of the natural filler, which is actively hydrophilic. The formation of additional shoulders in the 168 h-exposure case at 3400,3450 , and $3530 \mathrm{~cm}^{-1}$ can be attributed to the various forms of hydroxyl functional groups in the degradation products [21].

Similarly, an increase in the carbonyl $(\mathrm{C}=\mathrm{O})$ absorbance with an increasing exposure time can be seen (Fig. 3(b)) around the $1730 \mathrm{~cm}^{-1}$ region. The formation of these bands and evolution of additional shoulders is a direct consequence of the formation of the various forms of oxidation products with carbon oxygen linkages, including kenotic, carboxylic acid, and aldehydes $[\underline{8}, \underline{9}]$.

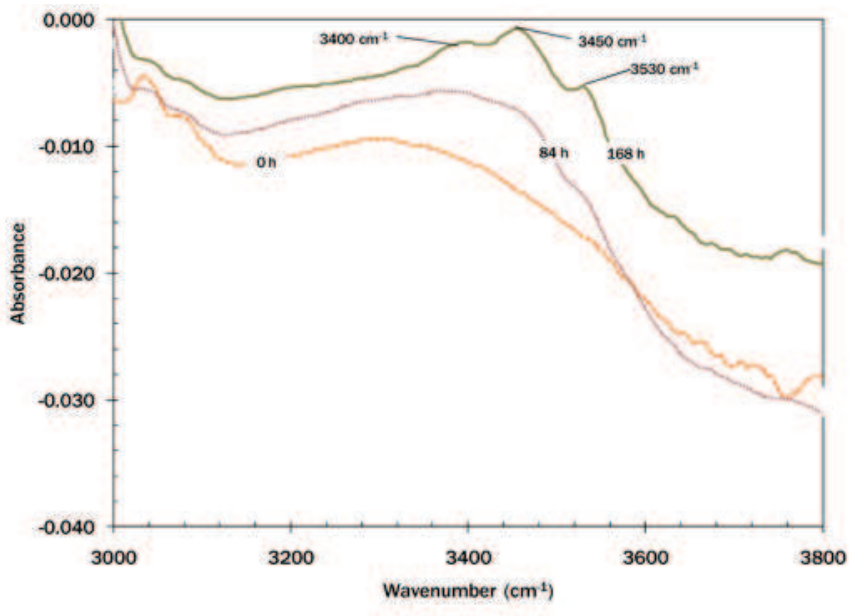

(a)

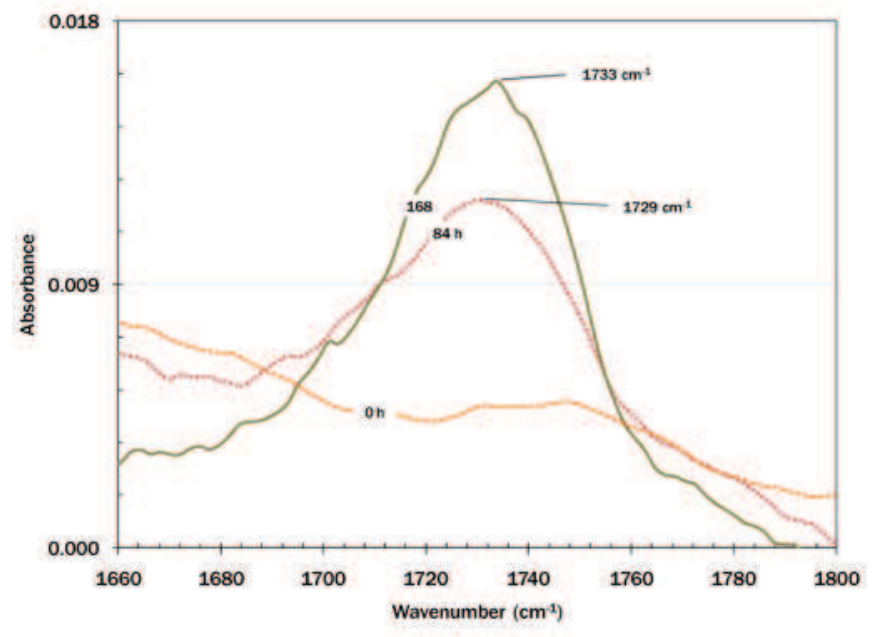

(b)

Fig. 3. FTIR spectra of (a) hydroxyl band and higher moisture absorption in ABS-S, also a combination of cellulosic linkages, (b) carbonyl band increasing absorbance.

\section{$\underline{\text { Discoloration }}$}

Discoloration is a common side effect of polymer oxidation and degradation that is caused by the presence and evolution of chromophores. Specifically in ABS, the formation of imide chromophores leads to yellowing of the polymer []․ To assess the degree of discoloration, colorimetry was performed on the unexposed and QUV exposed specimens and a yellowing index (YI) was calculated using Eqn. 1. Fig. 4 shows the YI for the three materials over the three exposure cases. Minimal change in color was observed in the ABSBlack specimens because of their inherent color. However, 
when ABS-S and ABS-N are compared, yellowing shows a stronger relationship with the duration of exposure in ABS-N over the ABS-S material. A very visible change is observed in YI from $0 \mathrm{~h}$ to $168 \mathrm{~h}$ for ABS-S and ABS-N, which show a $24 \%$ and $50 \%$ increase, respectively.

\section{MECHANICAL PROPERTIES}

The thermo-mechanical properties of the unexposed and exposed specimens were assessed in tension. A fundamental thermal property of the polymer reinforcement is the coefficient of linear thermal expansion, which is directly proportional to the mold shrinkage, and an indirect predictor of the material stiffness.

\section{Thermal Expansion}

Thermal expansion was measured using a tension film clamp in a DMA in the controlled force mode, with a temperature ramp. A minimal pre-load force was applied to grip the specimen $(12.7 \mathrm{~mm} \times 25.4 \mathrm{~mm} \times 4.0 \mathrm{~mm})$ and a temperature ramp at a heating rate of $5{ }^{\circ} \mathrm{C} / \mathrm{min}$ was applied. The displacement was recorded as a function of temperature. The slope of the displacement-temperature plot was used for CLTE measurements.

Fig. 5 shows the variation in the CLTE values over the three materials at $0 \mathrm{~h}$ and $168 \mathrm{~h}$ exposed conditions. At constant exposure times, a decrease in thermal expansion is seen in all materials in both cases. This decrease may be attributed to the presence of a heat stabilizer in the form of carbon black in ABS-B and the presence of natural filler in ABS-S, which also aids by means of increasing stiffness due to the resistance offered to polymer chain motion, and thereby reducing viscoelastic deformation.

Within each sample with exposure of $168 \mathrm{~h}$, the ABS-N and ABS-S show a slight increase in thermal expansion over ABS-B, which shows a decreased CLTE. This increase can be explained by considering a deeper penetration of degradation except ABS-B, where the surface degradation is reduced by the shielding effect of carbon black, as expected. Moreover, a decrease in ABS-B is also likely due to a local crystallization that occurs due to the formation of stiffer polymer segments that offer a media barrier and significantly reduce the rate of oxidation by limiting oxygen permeation [9]. In the case of ABS-N, the common mechanism of oxygen permeation and sequential propagation of chain scission can be surmised, whereas in case of ABS-S, the fibers may cause secondary crystallization, and increase local stiffness, similar to ABS-B.

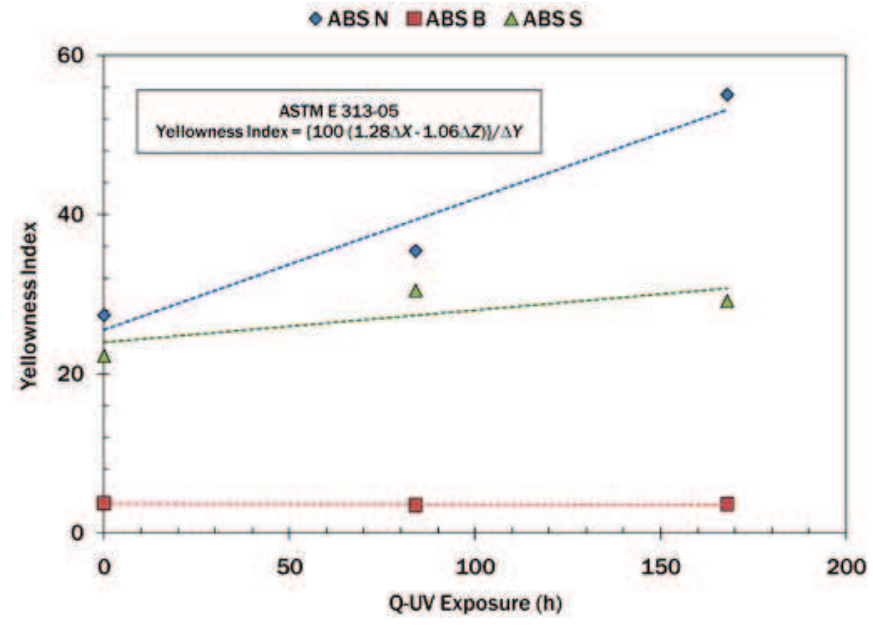

Fig. 4. Yellowness indices calculated for $0 \mathrm{~h}$-, $84 \mathrm{~h}$-, and 168 h-exposed materials according to ASTM E 313-05.

\section{Tensile Properties}

The tensile modulus and tensile strength of the material were obtained from ASTM D 638 tests on an Instron load frame (Instron \# 5567) at a constant crosshead movement rate of 5.0 $\mathrm{mm} / \mathrm{min}$ using ASTM D 638 Type-I specimens. Fig. 6(a) shows the tensile stress-strain characteristics of the three materials in the exposed condition. ABS-N and ABS-B showed a high elongation in the unexposed condition, while ABS-S showed a minimal plasticity.

However, the stress-strain characteristics revealed ABS-N losing its elongation characteristic, while ABS-B still showing high elongation. Fig. 6(a) shows the tensile modulus values of the materials in the unexposed and exposed conditions and Fig. 6(b) shows the tensile strength. On an average, in the unexposed condition, the tensile modulus of ABS-S showed a $25 \%$ increase, and tensile strength showed a $3 \%$ increase over the ABS-B and ABS-N samples. In the exposed condition, the ABS-S modulus was observed to be about $30 \%$ higher, and strength was about $5 \%$ lower than the ABS-B and ABS-N samples. The percentage elongation at break was not recorded for ABS-N and ABS-B as they did not exhibit failure consistently within the sample at $\varepsilon<5.0$ $(\mathrm{mm} / \mathrm{mm})$. The percentage elongation at failure decreased from $(3.77 \pm 0.57) \mathrm{mm} / \mathrm{mm}$ for unexposed $(0 \mathrm{~h})$ ABS-S to $(1.7 \pm 0.4) \mathrm{mm} / \mathrm{mm}$ for the $168 \mathrm{~h}$ exposed sample. The strain at maximum stress, as shown in Fig. 6(d), decreased within each sample with $168 \mathrm{~h}$ of exposure. As expected, ABS-S showed the lowest strain at maximum stress because of the particulate reinforcements.

The increase in the modulus is consistent with many previous research reports [ㄹ, 4]. These properties show the effectiveness of the additional of natural filler to the neat polymer. An increase in the modulus in the exposed condition also reinforces the benefit of natural filler, since increases in 
local stiffness due to the cellulose and lignin components in the reinforcement aid in extending its structural functionality to that of UV stabilization. This argument is supported by observations made in Fig.1(b), which shows a higher resistance to degradation by the ABS-S over ABS-N.

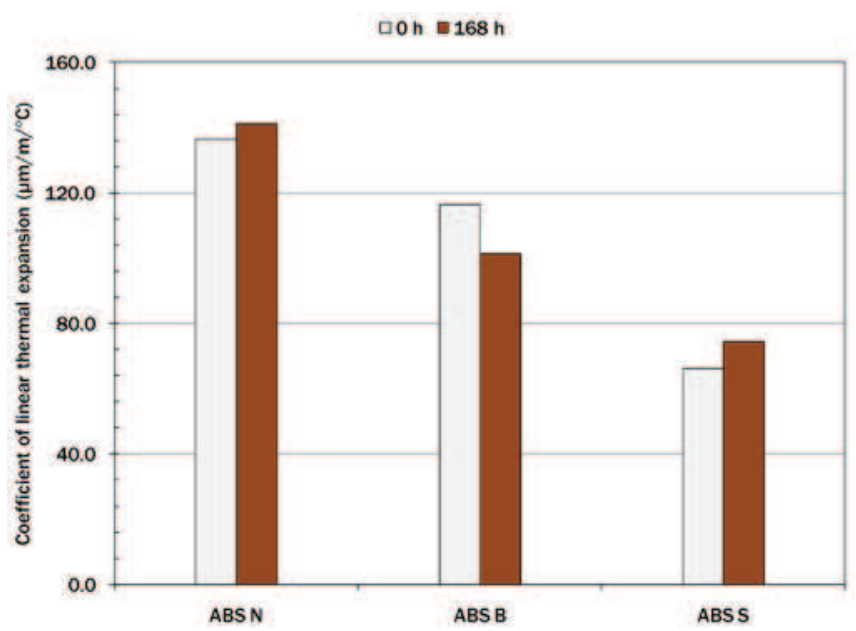

Fig. 5. The variation of coefficient of linear thermal expansion with a $168 \mathrm{~h}$ QUV conditioning for the three materials.

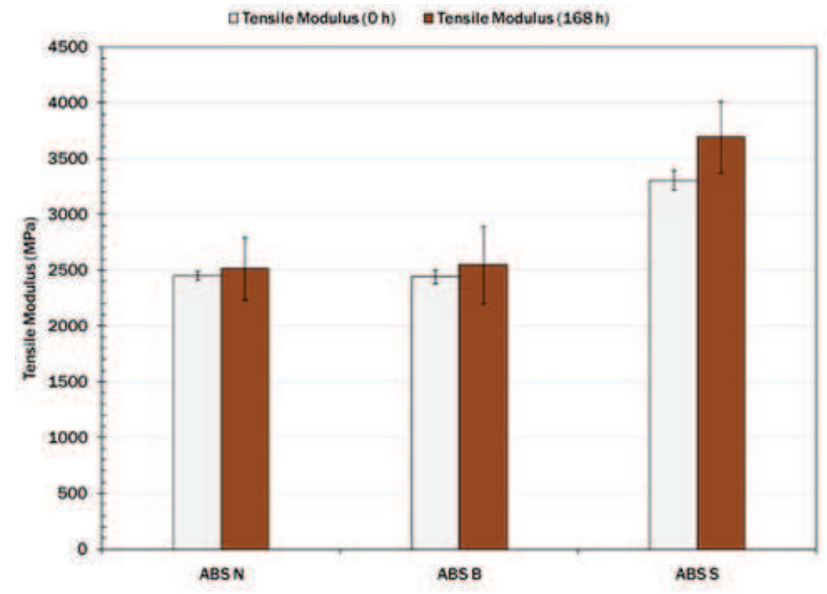

(a)

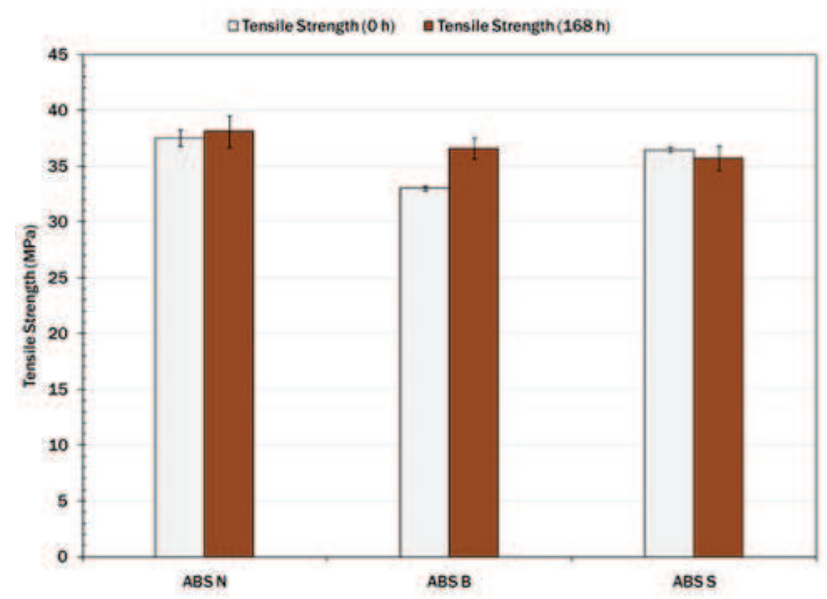

(b)

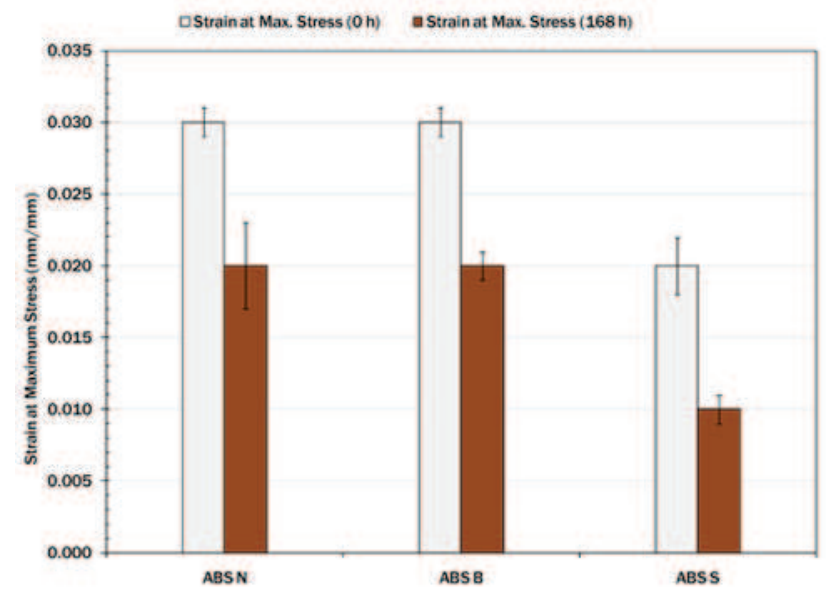

(c)

Fig. 6. (a) Tensile modulus, (b) tensile strength, and (c) strain at maximum stress of unexposed $(0 \mathrm{~h})$ and $168 \mathrm{~h}$ QUV conditioned materials. 


\section{CONCLUSIONS}

A thermo-mechanical analysis of natural fiber-filled ABS-S yields the following conclusions:

- ABS-S undergoes a comparable degree of degradation as carbon black-filled ABS-B, which is explained with the aid of FTIR spectroscopy.

- The yellowness index of ABS-S is a weak function of the QUV exposure duration, as opposed to ABS-N, which shows a stronger relationship with the conditioning.

- ABS-S shows a lower CLTE value in the exposed and unexposed conditions over ABS-N and ABS-B samples.

- A significant increase in Young's modulus and a marginal change in tensile strength are observed with the addition of 20 wt. \% fiber.

These results indicate that a lignocellulosic fiber incorporated into ABS can improve both UV stabilization and the modulus of elasticity at levels of $20 \mathrm{wt}$ \% fiber content. Further exploration into the mechanism of reinforcement and UV stabilization is needed in order to determine the optimal amount of bio-based fiber required for various levels of performance for certain applications.

\section{REFERENCES}

1. Bledzki, A.K. and Gassan, J., "Composites reinforced with cellulose based fibres." Progress in Polymer Science, 24(2): p. 221-274,1999.

2. Mohanty, A.K., Misra, M., and Drzal, L.T., Natural fibers, biopolymers, and biocomposites, Taylor \& Francis, Boca Raton, FL, 084931741X.

3. Fuqua, M.A. and Ulven, C.A., "Preparation and characterization of polypropylene Composites reinforced with modified lignocellulosic corn fiber," 2008. Providence, RI, United states: American Society of Agricultural and Biological Engineers.

4. Fuqua, M.A. and Ulven, C.A., "Characterization of polypropylene composites reinforced with modified lignocellulosic fiber," 2008. Long Beach, CA, United states: Soc. for the Advancement of Material and Process Engineering.

5. Fuqua, M.A. and Ulven, C.A., "Characterization of polypropylene/corn fiber composites with maleic anhydride grafted polypropylene." Journal of Biobased Materials and Bioenergy, 2(3): p. 258-263,2008.

6. Ashby, M.F. and Johnson, K., Materials and design : the art and science of material selection in product design, Butterworth-Heinemann, Oxford; Boston, 0750655542.

7. Scheirs, J. and Priddy, D., Modern styrenic polymers, Wiley, New York; Chichester, 04714975259780471497523.

8. Scheirs, J., Compositional and failure analysis of polymers : a practical approach, Wiley, Chichester; New York, 0471625345.
9. Hamid, S.H., Amin, M.B., and Maadhah, A.G., Handbook of polymer degradation, M. Dekker, New York, 0824786718 9780824786717.

10. Tiganis, B.E., et al., "Thermal degradation of acrylonitrile-butadiene-styrene (ABS) blends." Polymer Degradation and Stability, 76(3): p. 425-434,2002.

11. Davis, P., Tiganis, B.E., and Burn, L.S., "The effect of photo-oxidative degradation on fracture in ABS pipe resins." Polymer Degradation and Stability, 84(2): p. 233-242,2004.

12. Pickett, J.E., Gibson, D.A., and Gardner, M.M., "Effects of irradiation conditions on the weathering of engineering thermoplastics." Polymer Degradation and Stability, 93(8): p. 1597-1606,2008.

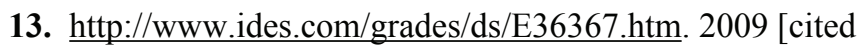
2009 August 6].

14. Q-LAB, http://www.q-lab.com/EN_Weblit/QUVLU-0819_2_web.pdf. 2009.

15. ASTM, ASTM D638 - 08 Standard Test Method for Tensile Properties of Plastics, in Plastics (I): D 256 - D 3159. 2008, ASTM International: West Conshohocken, PA.

16. http://www.tainstruments.com/product.aspx?

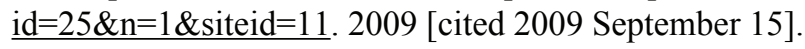

17. http://www.thermo.com/com/cda/product/detail/ $\underline{0,1055,115542,00 . \mathrm{html}} .2009$ [cited 2009 September 12].

18. ColousSpec, http://www.colourspec.com.au/ anz_CE7000A.pdf. 2009.

19. International, A.S.M., Characterization and failure analysis of plastics, ASM International, Materials Park, OH, 08717078969780871707895.

20. ASTM, ASTM E313-05 Standard Practice for Calculating Yellowness and Whiteness Indices from Instrumentally Measured Color Coordinates, in Paint - Tests for Chemical, Physical, and Optical Properties; Appearance. 2005, ASTM International: West Conshohocken, PA.

21. Oh, S.Y., et al., "FTIR analysis of cellulose treated with sodium hydroxide and carbon dioxide." Carbohydrate Research, 340(3): p. 417-428,2005.

\section{CONTACT INFORMATION}

Chad A. Ulven, Ph.D.

Assistant Professor

Mechanical Engineering and Applied Mechanics

North Dakota State University

Department 2490 Dolve Hall 111, PO Box 6050

Fargo, ND 58108-6050

Ph. 701-231-5641

chad.ulven@ndsu.edu 


\section{ACKNOWLEDGMENTS}

The authors would like to acknowledge the North Dakota Center of Excellence: SUNRISE Bioproducts for their financial support. Thanks are also due to Mr. Aron Fisk, Dr. Heidi Docktor, and Dr. Darrin Haagenson for their technical assistance. 